\title{
Nonlinear Modeling and Dynamic Analysis of a Hydro-turbine Governing System in the Process of Sudden Load Increase Transient
}

\author{
Huanhuan $\mathrm{Li}^{1}$, Diyi Chen ${ }^{1,2}$, Hao Zhang ${ }^{1}$, Feifei Wang ${ }^{1}$, Duoduo Ba ${ }^{1}$ \\ ${ }^{1}$ Institute of Water Resources and Hydropower Research, Northwest A\&F University, \\ Shaanxi Yangling 712100, P. R. China \\ ${ }^{2}$ Department of Mathematics and Statistics, Faculty of Science and Engineering \\ Curtin University, Perth Western Australia 6845, Australia
}

\section{Corresponding author: Diyi Chen}

Mailing Address: Institute of Water Resources and Hydropower Research, Northwest A\&F University, Shaanxi Yangling 712100, China

Telephones: 086-181-6198-0277

E-mail: diyichen@nwsuaf.edu.cn

\begin{abstract}
In order to study the nonlinear dynamic behaviors of a hydro-turbine governing system in the process of sudden load increase transient, we establish a novel nonlinear dynamic model of the hydro-turbine governing system which considers the elastic water-hammer model of the penstock and the second-order model of the generator. The six nonlinear dynamic transfer coefficients of the hydro-turbine are innovatively proposed by utilizing internal characteristics and analyzing the change laws of the characteristic parameters of the hydro-turbine governing system.
\end{abstract}


Moreover, from the point of view of engineering, the nonlinear dynamic behaviors of the above system are exhaustively investigated based on bifurcation diagrams and time waveforms. More importantly, all of the above analyses supply theoretical basis for allowing a hydropower station to maintain a stable operation in the process of sudden load increase transient.

Keywords: hydro-turbine; mathematical modeling; sudden load increase; dynamic transfer coefficients; nonlinear dynamics

\section{Introduction}

A hydro-turbine governing system (HTGS) is a complex nonlinear system, which is composed of synchronous generator, hydro-turbine, governor and penstock [1-3]. The dynamic quality of the HTGS is directly related to the safety, stability and economical operation of the hydropower station [4-8]. In recent years, with the development of hydroelectric power industry, a large number of hydropower stations with high water-head and large single unit have been built in China, which leads to the unstable problem of the HTGS [9-14]. Therefore, for the stable operation of the hydropower station, the study of the complex nonlinear dynamic behaviors of the HTGS has important theoretical significance and practical value.

Transition process is divided into large fluctuation process and small fluctuation process. In previous studies, the investigation of the transition process of the HTGS mainly focuses on the process of load rejection transient, which use linear model to indicate the dynamic behaviors of the HTGS in the small fluctuation process $[4-6,12]$. 
Whereas, the changes of system parameters affect the stability of the governing system, even these dynamical changes are very small [4, 15-24]. Apparently, this kind of simplified model is not enough to describe the complex dynamic characteristics of the HTGS. Also, for the large fluctuation process, the method of characteristic indicator of the hydro-turbine and the form of polynomial fitting are widely used in many published papers to investigate the relationship of characteristic parameters of the HTGS [23-27]. However, the mathematical models established by the above methods are not convenient to deeply analyze the dynamic characteristics of the HTGS [25-27]. Therefore, building a proper mathematical model becomes a necessary and difficult work.

Motivated by the above discussions, we have three advantages which make our approach attractive, comparing with the prior work. First, we creatively present six nonlinear dynamic transfer coefficients of the hydro-turbine. Second, a novel nonlinear dynamic mathematical model of the HTGS is established in the process of sudden load increase transient. Third, concentrating on the engineering significance, we investigate the nonlinear dynamic behaviors of the above system in detail.

The rest of the paper is organized as follows: In Section 2, a novel nonlinear dynamic mathematical model of the HTGS is proposed in the process of sudden load increase transient. We analyze the nonlinear dynamic behaviors of the established model in Section 3. Conclusions and discussion in Section 4 close the paper. 


\begin{tabular}{|c|c|c|c|}
\hline \multicolumn{4}{|c|}{ Nomenclature } \\
\hline \multirow[t]{2}{*}{$M_{t}$} & the mechanical torque of the & $E_{q}^{\prime}$ & the transient internal voltage of armature \\
\hline & hydro-turbine, N.m & $V_{s}$ & the voltage of infinite bus \\
\hline \multirow{2}{*}{$\begin{array}{l}H \\
n\end{array}$} & the hydro-turbine head, $\mathrm{m}$ & $x_{d}^{\prime}$ & the direct axis transient reactance \\
\hline & the hydro-turbine speed, $\mathrm{rad} / \mathrm{s}$ & $x_{q}$ & the quartered axis reactance \\
\hline$Q$ & the hydro-turbine flow, $\mathrm{m}^{3} / \mathrm{s}$ & $\alpha$ & the guide vane discharge angle, rad \\
\hline \multirow[t]{2}{*}{$m_{t}$} & the deviation of the mechanical & $b_{t}$ & the height of guide vane, $\mathrm{m}$ \\
\hline & torque of the hydro-turbine, p.u. & $F$ & the runner outlet area, $\mathrm{m}^{2}$ \\
\hline \multirow[t]{2}{*}{$h$} & the deviation of the hydro-turbine & $\beta_{0}$ & the runner intermediate flow surface angle, rad \\
\hline & head, p.u. & $r_{0}$ & the runner intermediate flow surface radius, $\mathrm{m}$ \\
\hline \multirow[t]{2}{*}{$x$} & the deviation of the hydro-turbine & $D_{0}$ & the guide vane pitch circle diameter, $\mathrm{m}$ \\
\hline & speed, p.u. & $L$ & the width of the guide vane, $\mathrm{m}$ \\
\hline \multirow[t]{2}{*}{$q$} & the deviation of the hydro-turbine & $Z_{0}$ & the number of the guide vane \\
\hline & flow, p.u. & $Y$ & the guide vane opening, rad \\
\hline \multirow{2}{*}{$\begin{array}{l}\delta \\
y\end{array}$} & the rotor angle, rad & $D_{1}$ & the runner diameter of the hydro-turbine, $\mathrm{m}$ \\
\hline & the deviation of the guide vane & $e_{m x}, \mathrm{e}_{m \mathrm{y}}$ & the partial derivatives of the hydro-turbine torque with \\
\hline & $\begin{array}{l}\text { opening, p.u. } \\
\text { the deviation of the generator }\end{array}$ & $e_{m \mathrm{~h}}$ & $\begin{array}{l}\text { respect to the hydro-turbine speed, the hydro-turbine } \\
\text { guide vane and the hydro-turbine head, p.u. }\end{array}$ \\
\hline \multirow{4}{*}{$\begin{array}{l}\omega \\
W \\
h_{w}\end{array}$} & rotor speed, p.u. & $e_{q x}, e_{q y}$ & the partial derivatives of the flow with respect to the \\
\hline & the generator rotor speed, $\mathrm{rad} / \mathrm{s}$ & $e_{q h}$ & hydro-turbine speed, the hydro-turbine guide vane and \\
\hline & the characteristic coefficient of & & the hydro-turbine head, p.u. \\
\hline & the pipeline & $k_{p}$ & the proportional adjustment coefficient \\
\hline \multirow{5}{*}{$\begin{array}{l}T_{a b} \\
T_{y} \\
u \\
\beta\end{array}$} & the mechanical starting time, $\mathrm{s}$ & $k_{i}$ & the integral adjustment coefficient \\
\hline & the engager relay time constant, $\mathrm{s}$ & $k_{d}$ & the differential adjustment coefficient \\
\hline & the output of the regulator & $Y_{k}$ & the main servomotor stroke \\
\hline & the normal angle of the guide & $d$ & the flow passage component \\
\hline & vane, rad & & \\
\hline \multirow[t]{2}{*}{$\eta$} & the efficiency & & \\
\hline & hydro-turbine, $\%$ & & \\
\hline
\end{tabular}

\section{A nonlinear dynamic model of the HTGS}

\subsection{Mathematical Model of the Francis Hydro-turbine}

The structure of the Francis hydro-turbine governing system [20] is shown in Fig.

1. 


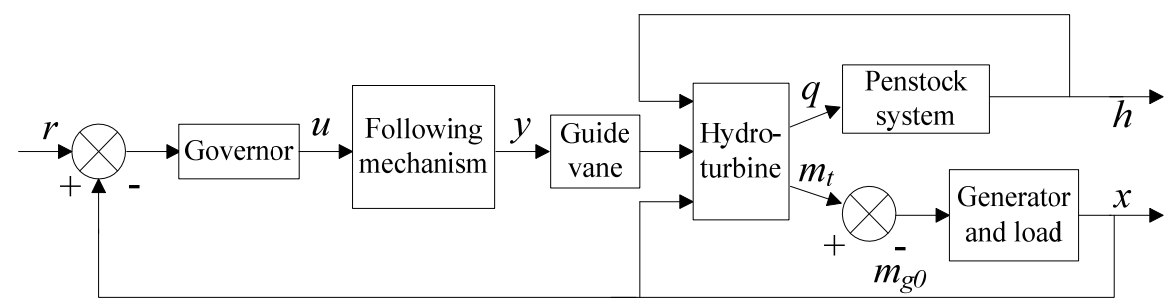

Fig. 1 The structure diagram of the Francis hydro-turbine governing system.

The dynamic characteristics of a Francis hydro-turbine $[6,20]$ can be described

as

$$
\left\{\begin{array}{l}
M_{t}=M_{t}(H, n, Y) \\
Q=Q(H, n, Y)
\end{array},\right.
$$

where $M_{t}, Q, H, n$ and $Y$ denote the mechanical torque of the hydro-turbine, the hydro-turbine flow, the hydro-turbine head, the hydro-turbine speed and the guide vane opening, respectively.

Utilizing the first-order of Taylor expansion of Eq. (1), and replacing the guide vane opening $(Y)$ with the main servomotor stroke $\left(Y_{k}\right)$, the dynamic characteristic expressions of the Francis hydro-turbine is obtained as

$$
\left\{\begin{array}{c}
m_{t}=e_{m w} x+e_{m y} y+e_{m h} h \\
q=e_{q w} x+e_{q y} y+e_{q h} h
\end{array}\right.
$$

where $m_{t}, q, h, x$ and $y$ denote the corresponding deviations of $M_{t}, Q, H$, $n$ and $Y$, respectively. $e_{m w}=\frac{\partial m_{t}}{\partial x}, e_{m y}=\frac{\partial m_{t}}{\partial y}$ and $e_{m h}=\frac{\partial m_{t}}{\partial h}$ denote the partial derivatives of the hydro-turbine torque with respect to the hydro-turbine speed, the hydro-turbine guide vane and the hydro-turbine head, respectively. $e_{q w}=\frac{\partial q}{\partial x}$, $e_{q y}=\frac{\partial q}{\partial y}$ and $e_{q h}=\frac{\partial q}{\partial h}$ denote the partial derivatives of the flow with respect to the hydro-turbine speed, the hydro-turbine guide vane and the hydro-turbine head, 
respectively.

\subsection{Mathematical Model of the Hydraulic Speed Regulation System}

There are many kinds of control modes for a governor, including the mode of PI regulation, series PID regulation and parallel PID regulation, and so on. In this paper, we consider a parallel PID governor as the controller, which is widely used in the HTGS. Suppose that the governor system is a non disturbance system, the output of the regulator $u$ can be expressed as

$$
u=-k_{p} \omega-k_{i} \int_{0}^{t} \omega d t-k_{d} \dot{\omega}=-k_{p} \omega-\frac{k_{i}}{\omega_{0}} \delta-k_{d} \dot{\omega},
$$

where $k_{p}, k_{i}$ and $k_{d}$ are the proportional, the integral and the differential adjustment coefficient, respectively.

The dynamic characteristics of the hydraulic servo system $[6,15]$ can be written as

$$
T_{y} \frac{d y}{d t}+y=u
$$

where $T_{y}$ and $u$ respectively denote the engager relay time constant and the output of the regulator.

Substituting Eq. (3) into Eq. (4), we can get

$$
\frac{d y}{d t}=\frac{1}{T_{y}}\left(-k_{p} \omega-k_{i} \int \Delta \omega-k_{d} \dot{\omega}-y\right) .
$$

\subsection{Mathematical Model of the Generator}

In this paper, we consider a second-order model of the generator, which can be represented as 


$$
\left\{\begin{array}{l}
\dot{\delta}=\omega_{0} \omega \\
\dot{\omega}=\frac{1}{T_{a b}}\left(m_{t}-m_{e}-D \omega\right)
\end{array}\right.
$$

where $\delta, \omega, D$ and $T_{a b}$ denote the rotor angle, the deviation of the generator rotor speed, the damping coefficient and the mechanical starting time, respectively. The electromagnetic torque of the generator $m_{e}$ is equal to its electromagnetic power $P_{e}$, that is

$$
m_{e}=P_{e}
$$

The electromagnetic power can be calculated with the following formula

$$
P_{e}=\frac{E_{q}^{\prime} V_{s}}{x_{d \Sigma}^{\prime}} \sin \delta+\frac{V_{s}^{2}}{2} \frac{x_{d \Sigma}^{\prime}-x_{q \Sigma}}{x_{d \Sigma}^{\prime} x_{q \Sigma}} \sin 2 \delta,
$$

where $E_{q}^{\prime}$ is the transient internal voltage of armature, $V_{s}$ is the voltage of infinite bus, $x_{d}^{\prime}$ is the direct axis transient reactance and $x_{q}$ is the quartered axis reactance, respectively. $x_{d \Sigma}^{\prime}$ and $x_{q \Sigma}$ in Eq. (8) are

$$
\left\{\begin{array}{l}
x_{d \Sigma}^{\prime}=\dot{x}_{d}+x_{T}+\frac{1}{2} x_{L} \\
x_{q \Sigma}=x_{q}+x_{T}+\frac{1}{2} x_{L}
\end{array},\right.
$$

where $x_{T}$ and $x_{L}$ are the short-circuit reactance of transformer and the transmission line reactance, respectively.

\subsection{Dynamic Equations of the Hydro-turbine Output Torque}

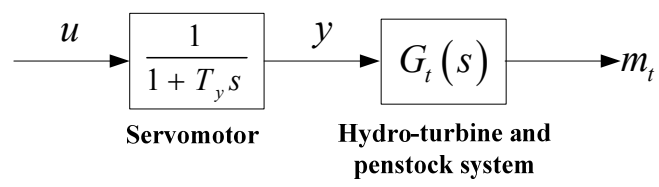

Fig. 2 The dynamic model of the hydro-turbine and penstock system. 
According to the Fig. 2 [20], considering the elastic water hammer, the transfer function of the penstock system can be written as

$$
G_{h}(s)=-2 h_{w} \frac{\frac{1}{48} T_{r}^{3} s^{3}+\frac{1}{2} T_{r} s}{\frac{1}{8} T_{r}^{2} s^{2}+1} .
$$

Thus, the transfer function between the hydro-turbine guide vane and the hydro-turbine output torque is

$$
G_{t}(s)=-\frac{e_{m y}}{e_{q h}} \cdot \frac{e s^{3}-\frac{3}{h_{w} T_{r}} s^{2}+\frac{24 e}{T_{r}^{2}} s-\frac{24}{h_{w} T_{r}^{3}}}{s^{3}+\frac{3}{e_{q h} h_{w} T_{r}} s^{2}+\frac{24}{T_{r}^{2}} s+\frac{24}{e_{q h} h_{w} T_{r}^{3}}},
$$

where $e$ is an intermediate variable, $e=\frac{e_{q y} e_{m h}}{e_{m y}}-e_{q h}, h_{w}$ is the characteristic coefficient pipeline, and $T_{r}$ is the elastic water hammer time constant.

Subsequently, the state-space equations of Eq. (11) can be shown as

$$
\left\{\begin{array}{l}
\dot{x}_{1}=x_{2} \\
\dot{x}_{2}=x_{3} \\
\dot{x}_{3}=-a_{0} x_{1}-a_{1} x_{2}-a_{2} x_{3}+y
\end{array} .\right.
$$

The dynamic equation of the hydro-turbine output torque can be described as

$$
m_{t}=b_{3} y+\left(b_{0}-a_{0} b_{3}\right) x_{1}+\left(b_{1}-a_{1} b_{3}\right) x_{2}+\left(b_{2}-a_{2} b_{3}\right) x_{3},
$$

where $\quad a_{0}=\frac{24}{e_{q h} h_{w} T_{r}^{3}}, \quad a_{1}=\frac{24}{T_{r}^{2}}, \quad a_{2}=\frac{3}{e_{q h} h_{w} T_{r}}, \quad b_{0}=\frac{24 e_{m y}}{e_{q h} h_{w} T_{r}^{3}}, \quad b_{1}=\frac{24 e e_{m y}}{e_{q h} T_{r}^{2}}$, $b_{2}=\frac{3 e_{m y}}{e_{q h} h_{w} T_{r}}$ and $b_{3}=-\frac{e e_{m y}}{e_{q h}} \cdot x_{1}, x_{2}$ and $x_{3}$ denote the intermediate variables, respectively.

\subsection{The Nonlinear Dynamic Expressions of Transfer Coefficients of the}

\section{Hydro-turbine}


Utilizing internal characteristics $[6,28]$ and the change laws of the characteristic parameters of the HTGS, we acquire the nonlinear relationship between the time $t$ and the transfer coefficients of the hydro-turbine in the process of sudden load increase transient.

The steady state equations of the Francis hydro-turbine [20] can be described as

$$
Q=\frac{W r_{0}^{2}+\frac{9.8 \eta H}{W}}{\frac{\operatorname{ctg} \alpha}{2 \pi b_{0}}+r_{0} \frac{\operatorname{ctg} \beta_{0}}{F}}
$$

and

$$
M_{t}=Q\left[\left(\frac{\operatorname{ctg} \alpha}{2 \pi b_{0}}+r_{0} \frac{\operatorname{ctg} \beta_{0}}{F}\right) Q-W r_{0}^{2}\right],
$$

where $H, M_{t}, W, Q$ and $\alpha$ denote the hydro-turbine head, the mechanical torque of the hydro-turbine, the generator rotor speed, the hydro-turbine flow and the guide vane discharge angle, respectively. $b_{t}, F, r_{0}$ and $\beta_{0}$ are the height of the guide vane, the runner outlet area, the runner intermediate flow surface radius and the runner intermediate flow surface angle, respectively.

Standardizing Eq. (14) and Eq. (15), the internal characteristics formulas of transfer coefficients of the hydro-turbine can be acquired as

$$
\begin{aligned}
& e_{q y}=\frac{a}{1+a-c} \cdot \frac{q_{0}^{2} \csc ^{2} \alpha_{0}}{\omega_{0}} \cdot \frac{Y_{r} Q_{r}}{2 \pi b_{t} r^{2} k_{0} W_{r}}, \\
& e_{q w}=\frac{a-1}{1+a-c} \cdot \frac{q_{0}}{\omega_{0}}, \\
& e_{q h}=\frac{1}{1+a-c} \cdot \frac{q_{0}}{h_{0}}, \\
& e_{m y}=b e_{q y},
\end{aligned}
$$




$$
e_{m w}=b e_{q w}-\frac{m_{t 0}}{\omega_{0}}
$$

and

$$
e_{m h}=b e_{q h}+\frac{m_{t 0}}{h_{0}}
$$

where subscripts $*, r$ and 0 denote the optimum operating condition, the actual value of rated condition and the actual value of steady condition, respectively. $q_{0}=\frac{Q_{0}}{Q_{r}}$, $h_{0}=\frac{H_{0}}{H_{r}}, \quad m_{t 0}=\frac{M_{t 0}}{M_{t r}}, \quad \omega_{0}=\frac{W_{0}}{W_{r}}, \quad r=0.353 D_{1}, \quad k_{0}=\left(\frac{d y}{d \alpha}\right)_{0} . \quad D_{1}$ is the runner diameter of the hydro-turbine.

We use the relationship between the guide vane opening $(Y)$ and the guide vane discharge angle $(\alpha)$ to get $k_{0}$ in Eq. (16), the guide vane opening $(Y)$ can be expressed as

$$
Y=D_{0} \sin \left(\frac{\beta}{2}\right) \sin \left(\alpha+\frac{\beta}{2}\right)-L \sin \left(\frac{\beta}{2}\right),
$$

where $D_{0}$ is the guide vane pitch circle diameter, $L$ is the width of the guide vane, $Z_{0}$ is the number of the guide vane, and $\beta$ is the normal angle.

The calculation formulas of $a, b$ and $c$ can be respectively written as

$$
\begin{aligned}
& a=\frac{\omega_{0}^{2}}{\eta_{0} h_{0}} \cdot \frac{r^{2} \omega_{r}^{2}}{9.81 H_{r}}, \\
& b=\left(1+\frac{c_{0}}{Q_{0}}\right) \frac{m_{t 0}}{q_{0}}
\end{aligned}
$$

and

$$
c=\frac{2 q_{0}\left(q_{0}-q_{*}\right) Q_{r}^{2}}{2 d \eta_{0}-\left(q_{0}-q_{*}\right)^{2} Q_{r}^{2}} .
$$


Here, we use the approximate relationship between the hydro-turbine flow $(Q)$ and the hydro-turbine efficiency $(\eta)$ to acquire $c$, and the relationship can be described as

$$
\eta=\eta_{*}-\frac{\left(q-q_{*}\right)^{2} Q_{r}^{2}}{2 d}
$$

where $d$ is the flow passage component.

It is well known that the expressions of the above six transfer coefficients of the hydro-turbine depend not only on its operation condition but also on the change law of the guide vane opening. In this paper, we address the dynamic characteristics of the HTGS in the process of sudden load increase transient. Here, the opening time of the guide vane is set for 5 second, and its opening law is shown in Fig. 3.

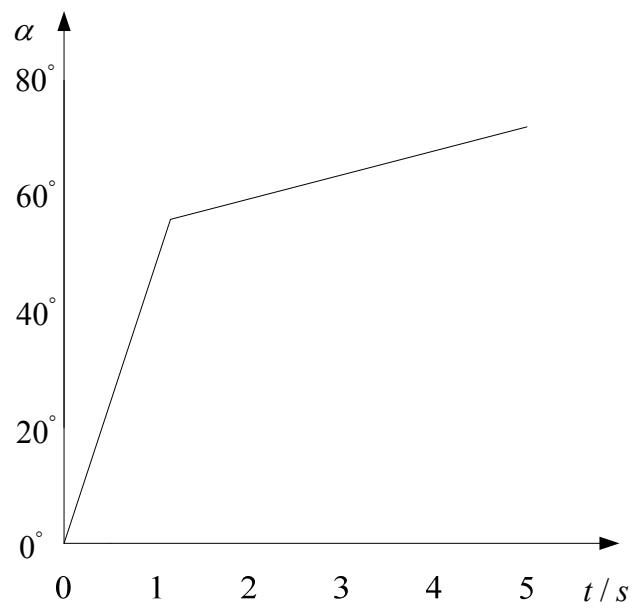

Fig. 3 The opening law of the guide vane in the process of sudden load increase transient.

For the sake of studying the change laws of the characteristic parameters of the HTGS in the process of sudden load increase transient, the relationship curves [20, 28-29] are shown in Fig. 4. 


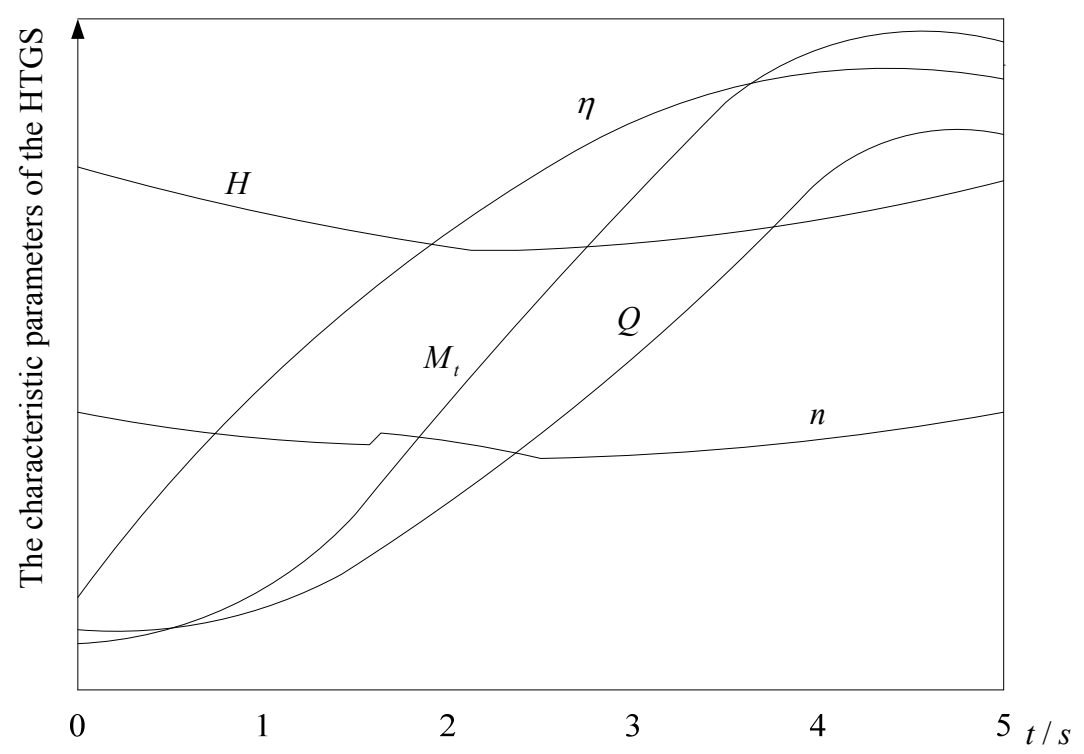

Fig. 4 The change laws of the characteristic parameters of the HTGS in the process of sudden load increase transient.

Utilizing the change laws of the characteristic parameters of the HTGS and considering the complex nonlinear characteristics of the HTGS in the process of sudden load increase transient, we introduce the trigonometric function and the exponential function to acquire the nonlinear dynamic expressions of six transfer coefficients of the hydro-turbine.

As shown in Fig. 4, in the initial stage of load increase transient process, the mechanical torque of the hydro-turbine $\left(M_{t}\right)$, the efficiency of the hydro-turbine $(\eta)$ and the hydro-turbine flow $(Q)$ respectively increase along with the increase of time $t$. Relatively speaking, the hydro-turbine head $(H)$ and the hydro-turbine speed $(n)$ have decreasing trends as time $t$ increases. The variation of the mechanical torque of the hydro-turbine $\left(M_{t}\right)$ is rather great, the variation of the hydro-turbine flow $(Q)$ is stronger than that of the hydro-turbine head $(H)$, and the variation of the 
hydro-turbine speed $(n)$ is particularly slow. Furthermore, the change laws of $M_{t 0}$, $H_{0}, Q_{0}$ and $N_{0}$ have respective direct ratio relations with $m_{t 0}, h_{0}, q_{0}$ and $n_{0}$, while $n_{0}$ is mostly proportional to $\omega_{0}$. Thus, we can acquire the change laws of $m_{t 0}, h_{0}, q_{0}$ and $\omega_{0}$.

From the above analyses, the change laws of the parameters of $a, b$ and $c$ can be obtained. The variations of $a$ and $c$ tend to decrease as time $t$ increases, but the variation of $b$ increases greatly with the increases of time $t$. Thus, we can assume that the value of $b$ tends to be a constant. Therefore, we can easily get that, in the initial stage of sudden load increase transient process, $\mathrm{e}_{q y}, e_{q w}, e_{m y}$ and $e_{m w}$ decrease with the increase of time $t$, while $e_{q h}$ and $e_{m h}$ increase gradually with the increasing time $t$.

Subsequently, in order to acquire the variation ranges of six transfer coefficients of the hydro-turbine, the variation curves of transfer coefficients of the hydro-turbine are shown in Fig. 5 [6].

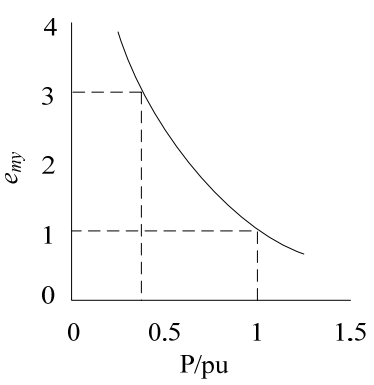

(a)

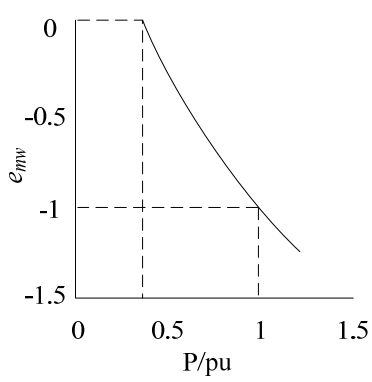

(b)

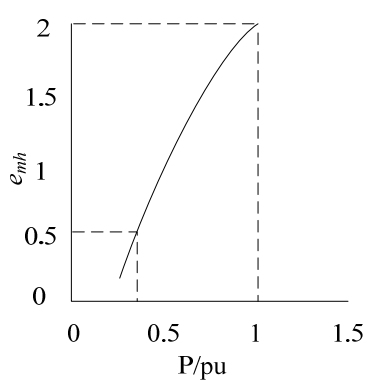

(c) 


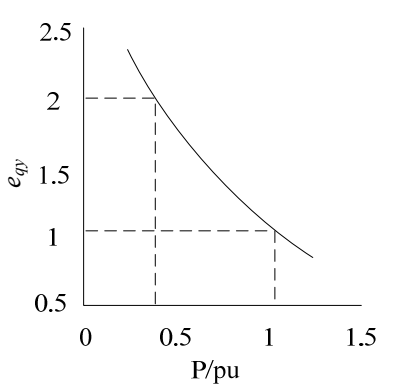

(d)

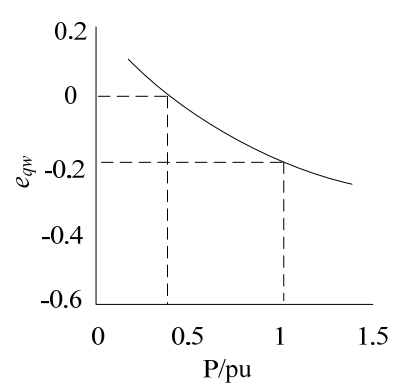

(e)

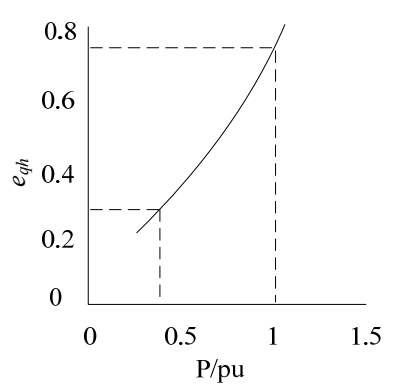

(f)

Fig. 5 Curves of six transfer coefficients of the hydro-turbine.

Based on the above discussions, we consider the complex nonlinear dynamic characteristics of the HTGS in the process of sudden load increase transient, the six novel nonlinear dynamic transfer coefficients of the hydro-turbine can be written as

$$
\begin{aligned}
& e_{m y}=\frac{1}{5} \cos 4 \pi t+2 e^{-t}+\frac{8}{5}, \\
& e_{m w}=\frac{1}{10} \cos 4 \pi t+\frac{9}{10} e^{-t}-\frac{7}{10}, \\
& e_{m h}=\frac{4}{25} \cos 4 \pi t-\frac{19}{10} e^{-t}+\frac{17}{10}, \\
& e_{q y}=\frac{2}{25} \sin 4 \pi t+\frac{4}{5} e^{-t}+\frac{7}{5}, \\
& e_{q w}=\frac{1}{50} \sin 4 \pi t+\frac{21}{100} e^{-t}-\frac{3}{20}
\end{aligned}
$$

and

$$
e_{q h}=\frac{1}{25} \sin 4 \pi t-\frac{13}{30} e^{-t}+\frac{3}{5}
$$

\subsection{Mathematical Model of the HTGS}

According to the reasonable analyses, we obtained the nonlinear expressions of six transfer coefficients of the hydro-turbine. Subsequently, combining every part of 
the HTGS into a single system, the nonlinear dynamic model of the HTGS in the process of sudden load increase transient can be written as

$$
\left\{\begin{array}{l}
\dot{x}_{1}=x_{2} \\
\dot{x}_{2}=x_{3} \\
\dot{x}_{3}=-\frac{24}{e_{q h} h_{w} T_{r}^{3}} x_{1}-\frac{24}{T_{r}^{2}} x_{2}-\frac{3}{e_{q h} h_{w} T_{r}} x_{3}+y \\
\dot{\delta}=\omega_{0} \omega \\
\dot{\omega}=\frac{1}{T_{a b}}\left(m_{t}-D \omega-\frac{E_{q}^{\prime} V_{s}}{x_{d \Sigma}^{\prime}} \sin \delta-\frac{V_{s}^{2}}{2} \frac{x_{d \Sigma}^{\prime}-x_{q \Sigma}}{x_{d \Sigma}^{\prime} x_{q \Sigma}} \sin 2 \delta\right) \\
\dot{m}_{t}=\frac{e e_{m y}}{e_{q h}} \frac{1}{T_{y}}\left(-k_{p} \omega-\frac{k_{i}}{\omega_{0}} \delta-k_{d} \dot{\omega}-y\right)+\left(\frac{24}{e_{q h} h_{w} T_{r}^{3}} \cdot \frac{3}{e_{q h} h_{w} T_{r}} \cdot \frac{e e_{m y}}{e_{q h}}-\frac{24}{e_{q h} h_{w} T_{r}^{3}} \cdot \frac{3 e_{m y}}{e_{q h} h_{w} T_{r}}\right) x_{1} \\
+\left(\frac{24 e_{m y}}{e_{q h} h_{w} T_{r}^{3}}-\frac{24}{e_{q h} h_{w} T_{r}^{3}} \cdot \frac{e e_{m y}}{e_{q h}}-\frac{24}{T_{r}^{2}} \cdot \frac{3 e_{m y}}{e_{q h} h_{w} T_{r}}+\frac{24}{T_{r}^{2}} \cdot \frac{3}{e_{q h} h_{w} T_{r}} \cdot \frac{e e_{m y}}{e_{q h}}\right) x_{2} \\
+\left(\frac{24 e e_{m y}}{e_{q h} T_{r}^{2}}-\frac{24}{T_{r}^{2}} \cdot \frac{e e_{m y}}{e_{q h}}-\frac{3}{e_{q h} h_{w} T_{r}} \cdot \frac{3 e_{m y}}{e_{q h} h_{w} T_{r}}+\left(\frac{3}{e_{q h} h_{w} T_{r}}\right)^{2} \cdot \frac{e e_{m y}}{e_{q h}}\right) x_{3}+\left(\frac{3 e_{m y}}{e_{q h} h_{w} T_{r}}-\frac{3}{e_{q h} h_{w} T_{r}} \cdot \frac{e e_{m y}}{e_{q h}}\right) y \\
\dot{y}=\frac{1}{T_{y}}\left(-k_{p} \omega-\frac{k_{i}}{\omega_{0}} \delta-k_{d} \dot{\omega}-y\right)
\end{array} .\right.
$$

\section{Nonlinear dynamic analyses}

In this section, we focus on analyzing the operation characteristics of the HTGS considering engineering practices. Keep the PID parameters in a limited range, and the numerical experiments are carried out by using Runge-Kutta method. The Runge-Kutta method, which is widely applied in numerical experiments of engineering, is mainly used to simulate the solutions of differential equations utilizing the theory of iteration. Moreover, it has the characteristic of high precision. Runge-Kutta formulas can be found in Ref. [29-33]. The iteration step is 2000; the time step is 0.01 ; and the initial value is $(0,0,0,0.001,0.001,0,0)$.

Based on many published papers, the system parameters are initially selected [4, $6,12,14-15,20]$. Subsequently, considering the nonlinear characteristics of the HTGS 
and the dynamic transfer coefficients of the hydro-turbine, the system parameters are finally determined by multi-simulation experiments $[6,14-15,20]$. System parameters are as follows

$$
\begin{aligned}
& w_{0}=314, \quad D=0.5, \quad E_{q}^{\prime}=4, x_{d \Sigma}^{\prime}=1, x_{q \Sigma}^{\prime}=2, V_{s}=1, T_{y}=1, T_{r}=0.51, h_{w}=2.5, T_{a b}=7, \\
& k_{P}=2+0.5 t, \quad k_{i}=1, \quad k_{d}=5 .
\end{aligned}
$$

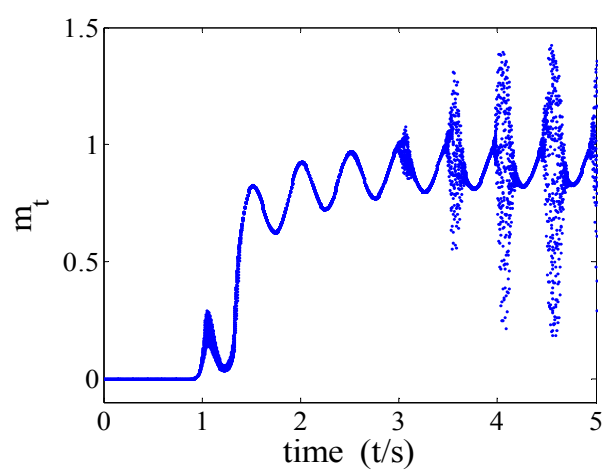

(a) Bifurcation diagram of $m_{t}-t$.

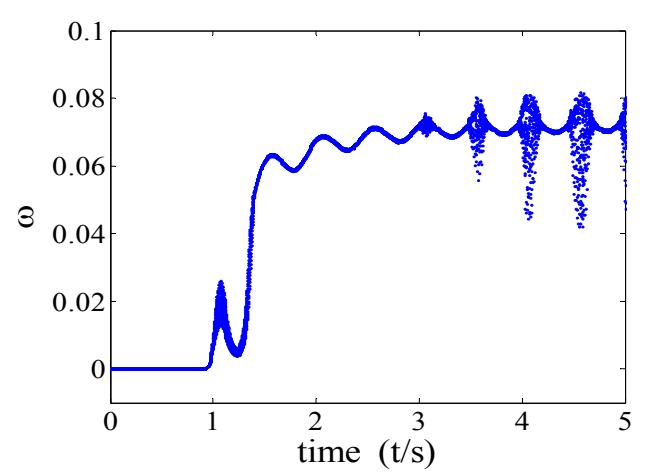

(b) Bifurcation diagram of $\omega-t$.

Fig. 6 Bifurcation diagrams of the HTGS with time $t$. (a) Bifurcation diagram of $m_{t}-t ;(b)$

$$
\text { Bifurcation diagram of } \omega-t \text {. }
$$

The dynamic response of the mechanical torque of the hydro-turbine is illustrated in Fig. 6(a) in the process of sudden load increase transient. For $0 \leq t<0.947$, the variation range of the deviation of the mechanical torque of the hydro-turbine $\left(m_{t}\right)$ is $0 \leq m_{t}<0.01$. When $0.947 \leq t<1.55$, the deviation of the mechanical torque of the hydro-turbine $\left(m_{t}\right)$ quickly increases, whose maximum deviation reaches to 0.86 . For $1.55 \leq t<5$, a fluctuant ascending phenomenon of the deviation of the mechanical torque of the hydro-turbine $\left(m_{t}\right)$ with time $t$ appears.

Overall, the general trend of the deviation of the mechanical torque of the hydro-turbine $\left(m_{t}\right)$ is continuously increasing. In other words, when the HTGS enters 
into the process of sudden load increase transient, the guide vane opening and the hydro-turbine flow both increase gradually as time $t$ goes on. Meanwhile, the mechanical torque of the hydro-turbine $\left(m_{t}\right)$ increases with the increase of time $t$. Interestingly, the numerical fluctuations of the deviation of the mechanical torque of the hydro-turbine $\left(m_{t}\right)$ appears in $3 \leq t \leq 5$. More specially, the complex nonlinear phenomenon becomes more obvious with the increase of time $t$. It means that the HTGS gets out of control gradually.

Fig. 6(b) shows, for $0 \leq t<0.947$, the deviation of the generator rotor speed $(\omega)$ fluctuates around zero. It indicates that the HTGS keeps in a stable state under the appropriate control of the PID governor. As regards $0.947 \leq t \leq 5$, the deviation of the generator rotor speed $(\omega)$ has an increasing trend, meaning that the HTGS cannot smoothly tend to its steady state. Note that the numerical fluctuations of the deviation of the generator rotor speed $(\omega)$ occurs in $1.55<t<5$. Also, the phenomenon of chaos becomes more obvious as time $t$ increases, which means that the stability of the HTGS gradually deteriorates along with the increase of time $t$ in the process of sudden load increase transient.

From Fig. 6, note that the fluctuations of the deviations of the mechanical torque of the hydro-turbine $\left(m_{t}\right)$ and the generator rotor speed $(\omega)$ both appear suddenly in $1<t<1.25$. The reason for these phenomena may be the sudden change of the opening law of the guide vane. In other words, the hydro-turbine flow usually produces an abrupt change at the turning point of the opening speed of the hydro-turbine guide vane transiting from fast to slow. Subsequently, the water hammer in the penstock 
markedly increases, which leads to a sudden numerical fluctuation of the HTGS.

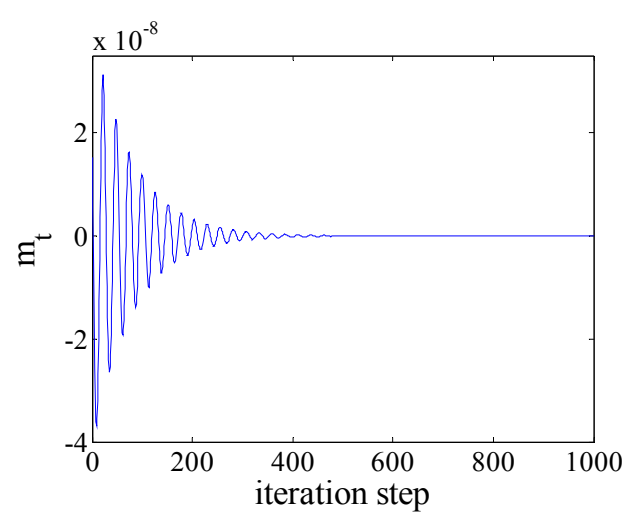

(a) Time waveform of $m_{t}-t$.

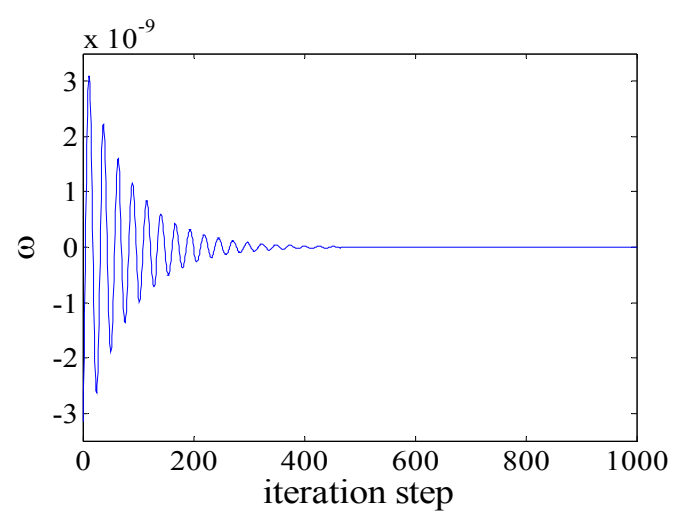

(b) Time waveform of $\omega-t$.

Fig. 7 Time waveforms of the HTGS with $t=0$. (a) Time waveform of $m_{t}-t ;(b)$ Time waveform of

$\omega-t$.

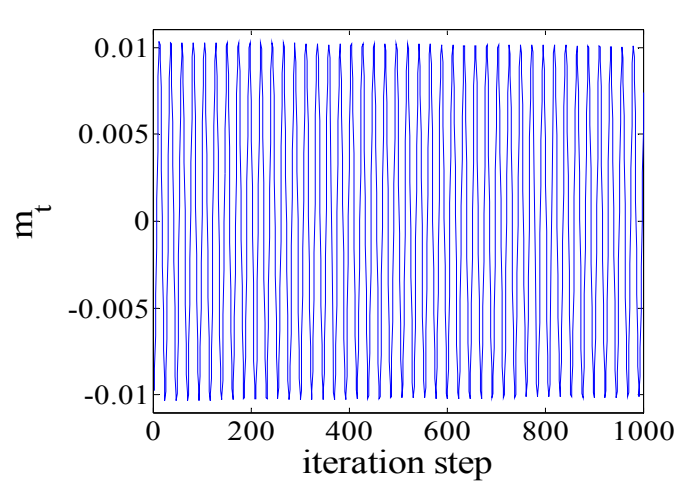

(a) Time waveform of $m_{t}-t$.

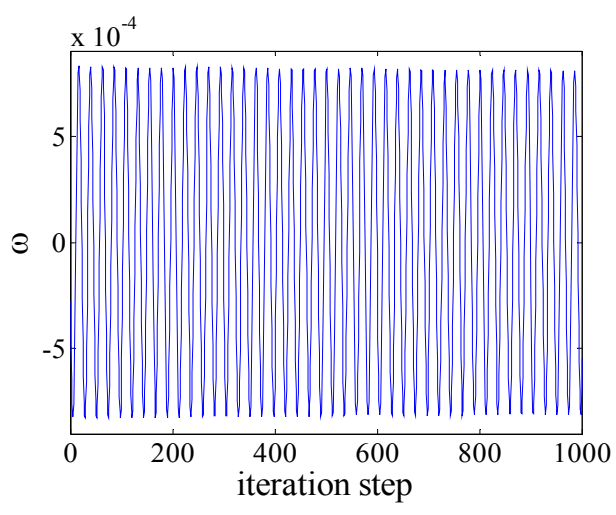

(b) Time waveform of $\omega-t$.

Fig. 8 Time waveforms of the HTGS with $t=0.947$. (a) Time waveform of $m_{t}-t$; (b) Time waveform of $\omega-t$.
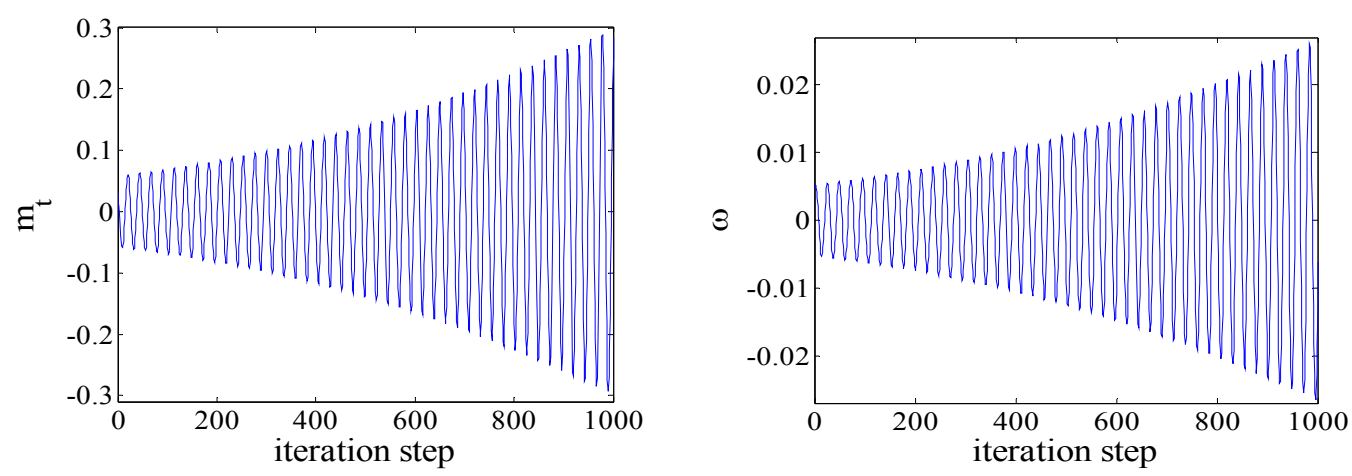
Fig. 9 Time waveforms of the HTGS with $t=1.063$. (a) Time waveform of $m_{t}-t$; (b) Time waveform of $\omega-t$.

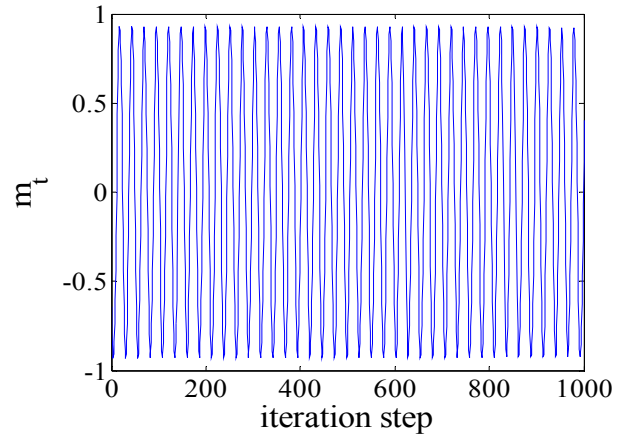

(a) Time waveform of $m_{t}-t$.

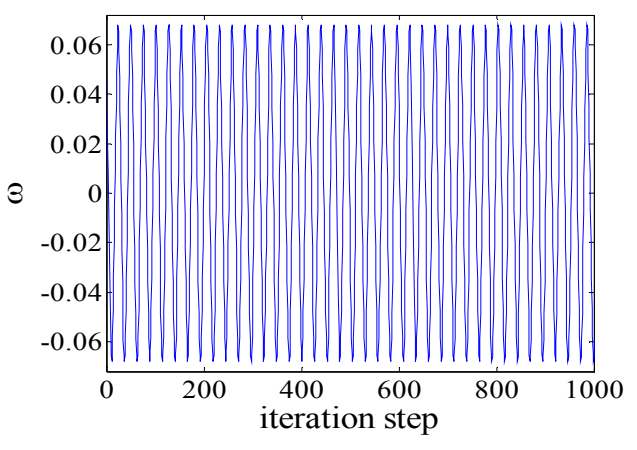

(b) Time waveform of $\omega-t$.

Fig. 10 Time waveforms of the HTGS with $t=2$. (a) Time waveform of $m_{t}-t ;(b)$ Time waveform of $\omega-t$

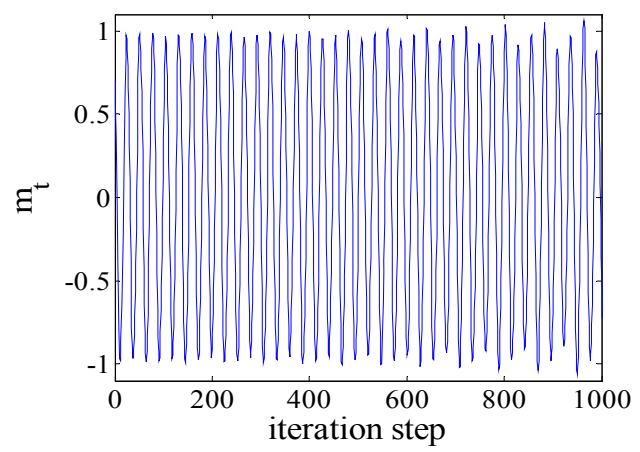

(a) Time waveform of $m_{t}-t$.

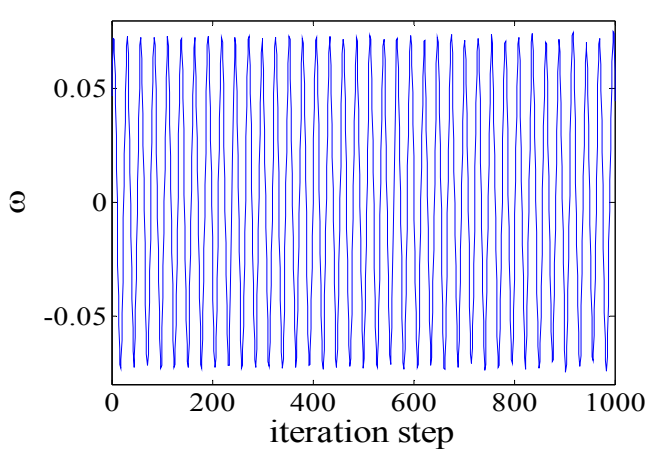

(b) Time waveform of $\omega-t$.

Fig. 11 Time waveforms of the HTGS with $t=3.05$. (a) Time waveform of $m_{t}-t ;(b)$ Time waveform of $\omega-t$. 


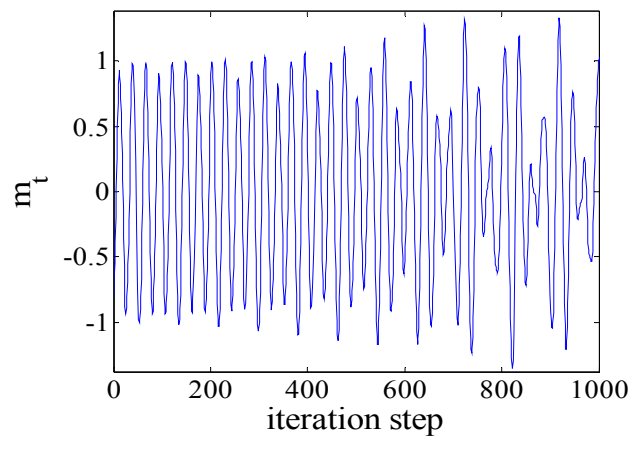

(a) Time waveform of $m_{t}-t$.

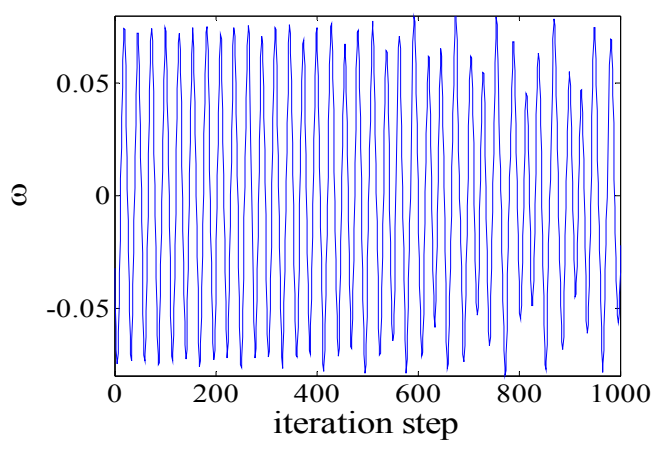

(b) Time waveform of $\omega-t$.

Fig. 12 Time waveforms of the HTGS with $t=4.6$. (a) Time waveform of $m_{t}-t ;(b)$ Time waveform of

$$
\omega-t
$$

In order to illustrate the dynamic behaviors of the HTGS clearly, we obtain the time waveforms of the HTGS. The time waveform diagrams reflect variation trends of the governing system at distinct times. We choose six representative times, which have the different dynamic behaviors. Subsequently, the dynamic behaviors of the HTGS are studied in detail in Figs. 7-12.

Fig. 7 shows, the deviations of the mechanical torque of the hydro-turbine $\left(m_{t}\right)$ and the generator rotor speed $(\omega)$ both tend to be a constant at $t=0$ second, meaning that the HTGS tends to be stable. The dynamic behaviors of the HTGS at $t=0.947$ second are shown in Fig. 8. The motion regularities of the mechanical torque of the hydro-turbine and the generator rotor speed are periodical. And from Fig. 9, it can be observed that the deviations of the mechanical torque of the hydro-turbine $\left(m_{t}\right)$ and the generator rotor speed $(\omega)$ increase gradually, which indicates the HTGS cannot operate safely and stably. In addition, according to Fig. 6 , we can easily get that the unstable motion state of the HTGS continues to $t=1.55$ second. Then the HTGS goes 
into more complex motions.

As shown in Fig. 10, we investigate the dynamic characteristics of the HTGS at $t=2$ second. The mechanical torque of the hydro-turbine and the generator rotor speed both make a periodic vibration, which means that the HTGS is in the critical state. That is to say, for $1.55<t<3$, the HTGS cannot operate safely and stably. The stability of the HTGS becomes more sensitive to the changes of the characteristic parameters of the HTGS.

Fig. 11 shows that the dynamic behaviors of the mechanical torque of the hydro-turbine and the generator rotor speed are similar, whose peak clippings both appear. However, the difference is that the phenomenon of the chaos of the mechanical torque of the hydro-turbine is more obvious compared with the generator rotor speed, which may be caused by the situation that the variation degree of mechanical torque of the hydro-turbine is greater than that of the generator rotor speed. From Fig. 12, we can know that the clipping phenomena become more apparent. It indicates that the HTGS gets completely out of control.

From the above analyses and discussions, we obtain that the established mathematical model of the HTGS in the process of sudden load increase transient accords with the corresponding theories and engineering practices [15, 28-29]. In order to illustrate the reliability and accuracy of numerical results, we further study the zero-pole distributive charts of the HTGS at some representative times.

\section{Remark 1:}




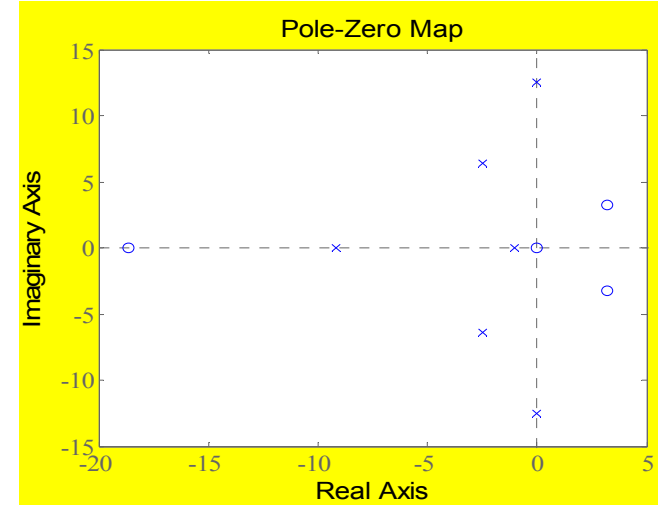

(al) $t=0$.

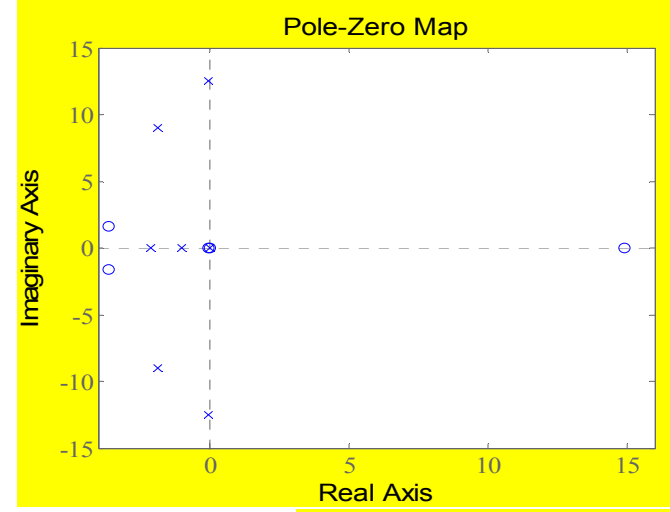

(b) $t=0.947$.

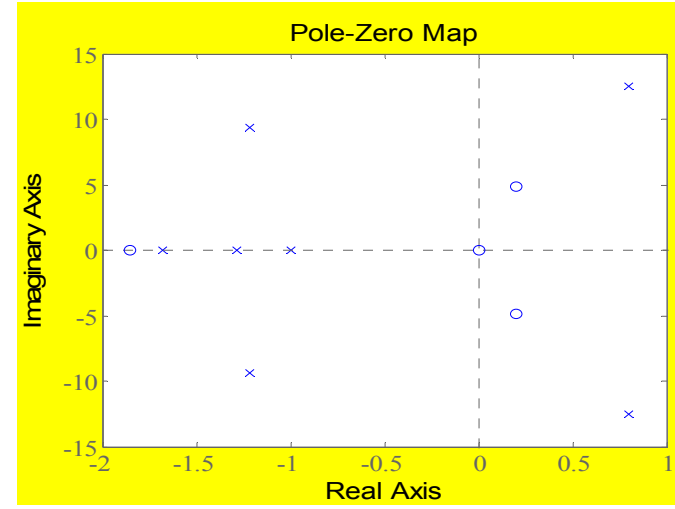

(d) $t=4.6$.

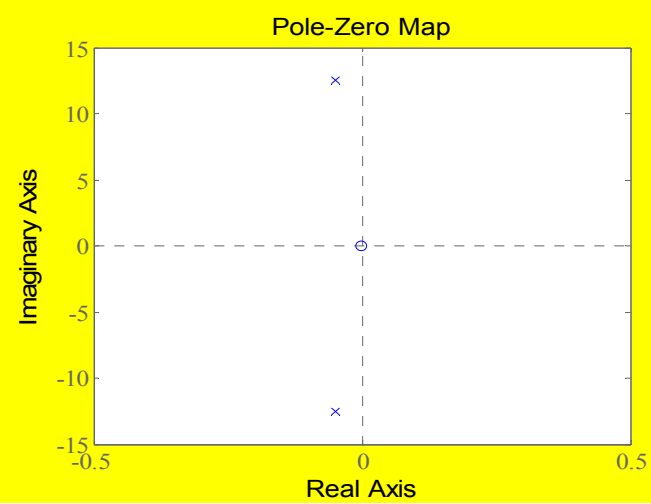

(a2) Local amplification with $t=0$.

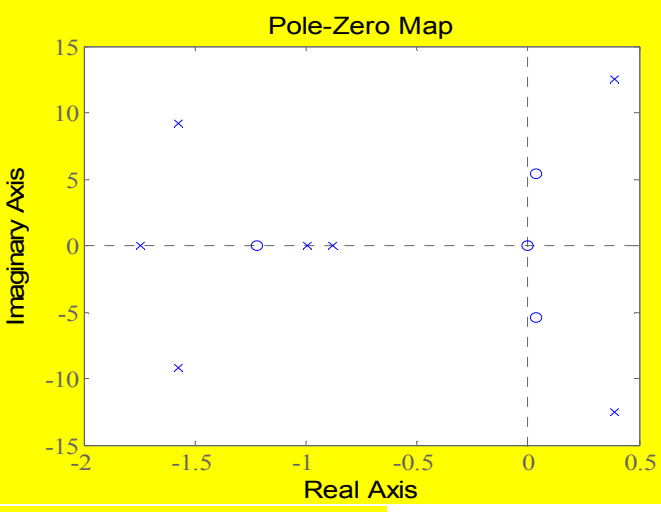

(c) $t=1.063$.

Fig. 13 Zero-pole distributive charts of the HTGS at different representative times. (a1) $t=0 ;(a 2)$

Local amplification with $t=0$; (b) $t=0.947$; (c) $t=1.063$; (d) $t=4.6$.

Based on the numerical experiments, the characteristics of the pole distributions at $t=0.947$ and $t=3.05$ are similar to the characteristics of the pole distributions at $t=2$ 
and $t=4.6$, respectively. To make the paper readable, we only show the pole-zero maps at $t=0.947$ and $t=4.6$. The zero-pole distributive charts of the HTGS at different representative times $(t=0, t=0.947, t=1.063, t=4.6)$ are shown in Fig. 13.

Figs. 13(a1) and (a2) show the zero-pole distributive charts of the HTGS at $t=0$. It is clearly observed that all poles are located in the left-half plane. It reveals that the HTGS is stable. This result is identical with Fig. 7. At $t=0.947$, as shown in Fig. 13(b), there is a pole at the origin, and the other poles lie in the left-half plane of the zero-pole distributive chart. From the bifurcation diagrams and time waveform at $t=0.947$, we draw a conclusion that the HTGS is in the critical state. As Figs. 13(c) and $(d)$ show, two poles appear in the right-half plane, which means that the HTGS is unstable. This result is in good agreement with Fig. 9 and Fig. 12. All the above numerical results indicate that the HTGS changes from steady state to instability. Therefore, the result of numerical experiments is reliable.

\section{Remark 2:}

In this paper, the novel mathematical model can better reflect the essence of the nonlinear system compared with some previous mathematical models of the HTGS. Therefore, a comparison between a previous mathematical model [6] and the novel mathematical model of the HTGS has been presented.

First, we introduce the previous mathematical model of the HTGS [6]. In order to make the comparison clearer, the active time of transfer coefficients of the hydro-turbine is 5 seconds. Moreover, we carry out the numerical experiments by keeping the system parameters of the HTGS unchanged in this paper. Finally, 
numerical results can be shown in the bifurcation diagrams and time waveform diagrams, namely Figs. 14-15.

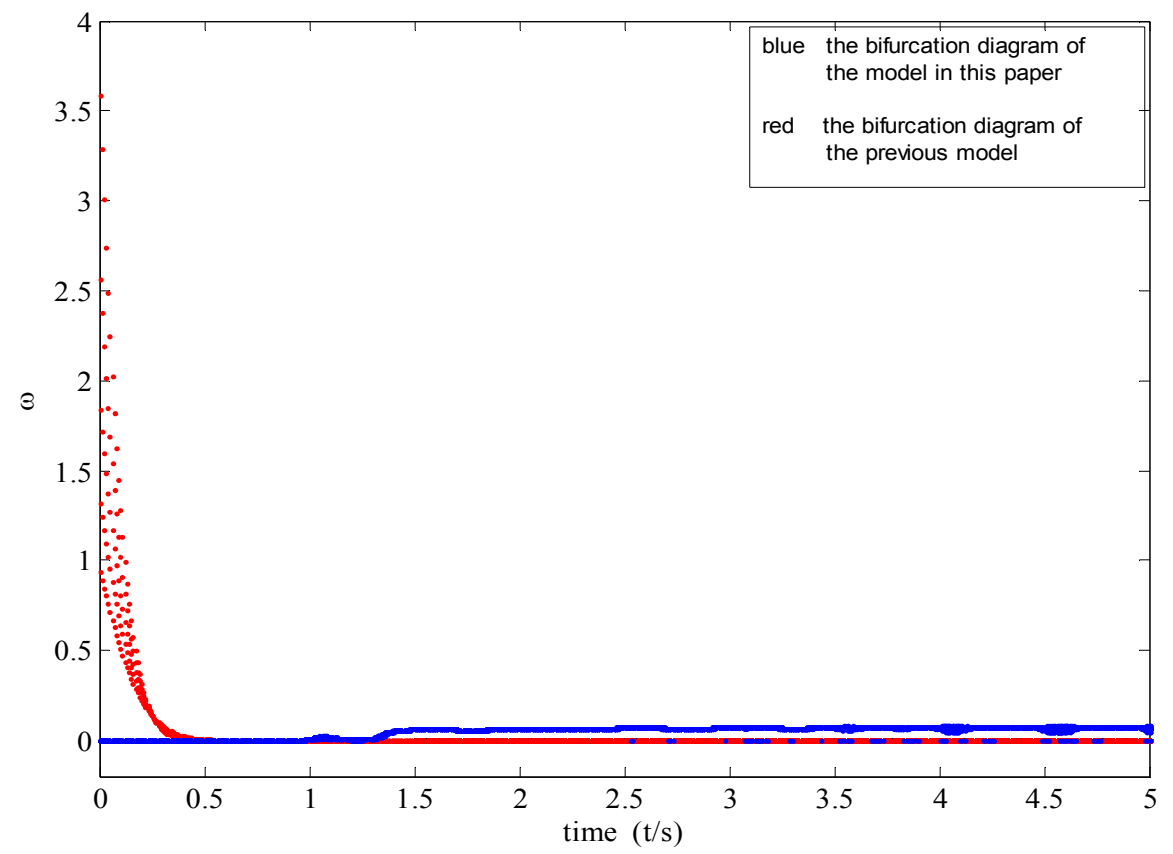

Fig. 14 The comparison of bifurcation diagrams of the HTGS between the novel mathematical model and the previous mathematical model.

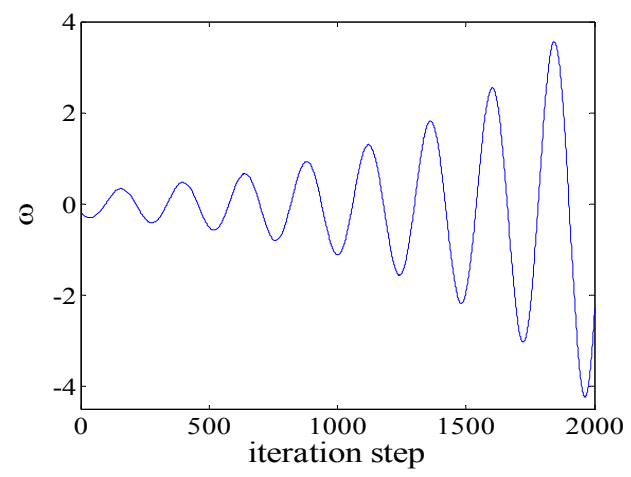

(a) Time waveform of $\omega-t$ at $t=0$.

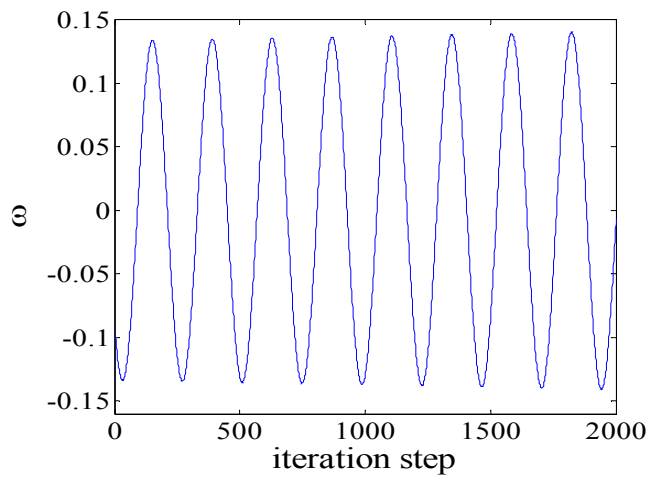

(b) Time waveform of $\omega-t$ at $t=0.25$. 


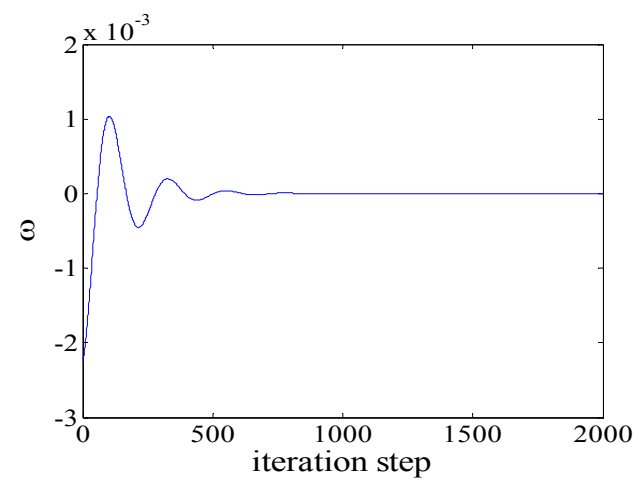

(c) Time waveform of $\omega-t$ at $t=1$.

Fig. 15 Time waveforms of the HTGS of the previous mathematical model. (a) Time waveform of $\omega-t$ at $t=0 ;(b)$ Time waveform of $\omega-t$ at $t=0.25$; (c) Time waveform of $\omega-t$ at $t=1$.

For the previous mathematical model, as shown in Figs. 14-15, the variation range of the deviation of generator rotor speed $(\omega)$ is $0 \leq \omega \leq 3.58$ when $0 \leq t \leq 0.25$. Moreover, the motion regularity of the generator rotor speed is diverging, indicating that the violent vibration of the HTGS occurs. Differently, for the novel mathematical model, the deviation of generator rotor speed $(\omega)$ fluctuates around zero as $0 \leq t \leq 0.25$. Whereas, the fact is that the generator rotor speed cannot change violently because of the connection with the power system in the process of sudden load increase transient. For $0.25<t \leq 5$, the deviation of generator rotor speed $(\omega)$ of the previous mathematical model varies around a tiny neighbor region of zero. The HTGS changes from a critical state to a stable state. Correspondingly, for the novel mathematical model of the HTGS, its deviation of generator rotor speed $(\omega)$ fluctuates slightly for $0.25<t \leq 5$, and its maximum value is 0.08 . However, from the view point of the engineering, the system parameters cannot keep unchanged for such a long time in the transition process. Therefore, the novel mathematical model of 
the HTGS can better reflect the dynamical characteristics of the governing system comparing with the previous mathematical model.

\section{Conclusions and discussion}

First, considering the transfer coefficients of the hydro-turbine vary with the operational conditions of the HTGS, we have innovatively proposed the nonlinear transfer coefficients of the hydro-turbine in the process of sudden load increase transient based on internal characteristics method. Second, a novel nonlinear mathematical model of the HTGS has been established in the process of sudden load increase transient. Finally, from the point of view of engineering, we have investigated the nonlinear dynamic behaviors of the HTGS using bifurcation diagrams and time waveforms. According to the numerical experiments results, we get the following conclusions.

(1) From the bifurcation diagrams, we can see, for $0 \leq t<0.947$, the HTGS tends to be stable under the action of PID governor. When $0.947 \leq t \leq 5$, the HTGS cannot maintain a stable state. Note that the stability of the HTGS turns to be worse as time $t$ increases, and the nonlinear characteristics of the HTGS are more obvious with the increasing time $t$.

(2) Time waveforms show, the motion regularities of the HTGS are convergent, periodical and divergent at $t=0$ second, $t=0.947$ second and $t=1.063$ second, respectively. It means that the HTGS changes from the stable state to the unstable state. When $t=2$ second, the HTGS cannot keep stable. More specially, for $t=3.05$ second and $t=4.6$ second, the emergence of the chaos indicates that the HTGS gets out 
of control.

(3) Note that there are numerical fluctuations for $1<t<1.25$ and $1.55<t<3$, respectively. For $1<t<1.25$, the numerical fluctuations are caused by the sudden change of the opening law of the guide vane. For $1.55<t<3$, the numerical fluctuations are caused by the comprehensive result of the characteristic parameters of the HTGS.

In this paper, the PID parameters are limited in a certain range. Therefore, in order to adapt to the change of the load of the HTGS, the stable region of the control parameters will be studied in our future work. Moreover, we will further study the dynamic behaviors of the HTGS in the last stage of sudden load increase transient process.

\section{Acknowledgements}

This work was supported by the scientific research foundation of National Science Foundation (51479173, 51279167), Fundamental Research Funds for the Central Universities (201304030577), Scientific research funds of Northwest A\&F University (2013BSJJ095), the scientific research foundation on water engineering of Shaanxi Province (2013slkj-12) and the Science Fund for Excellent Young Scholars from Northwest A\&F University.

\section{References}

[1] C.W. Jiang, Y.C. Ma, PID controller parameters optimization of hydro-turbine governing systems using deterministic-chaotic-mutation evolutionary programming (DCMEP), Energy Convers. Manage. 47(2006) 1222-1230. 
[2] N. Kishor, Nonlinear predictive control to track deviated power of an identified NNARX model of a hydro plant, Expert Syst. Appl. 35(2008) 1741-1751.

[3] K. Nagode, I. Skrjanc, Modelling and internal fuzzy model power control of a francis water turbine, Energies 17(2014) 874-89.

[4] D.Y. Chen, C. Ding, X.Y. Ma, P. Yuan, D.D. Ba, Nonlinear dynamical analysis of hydro-turbine governing system with a surge tank, Appl. Math. Model. 37(2013) 7611-7623.

[5] C.S. Li, J.Z. Zhou, Parameters identification of hydraulic turbine governing system using improved gravitational search algorithm, Energy Convers. Manage. 52(2011) 374-381.

[6] H. Zhang, D.Y. Chen, B.B. Xu, F.F. Wang, Nonlinear modeling and dynamic analysis of hydro-turbine governing system in the process of load rejection transient, Energy Conv. Manag. 90(2015) 128-137.

[7] P. Pennacchi, P. Borghesani, S. Chatterton, A cyclostationary multi-domain analysis of fluid instability in Kaplan turbines, Mech. syst. Signal Pr. 60-61(2015) 375-390.

[8] X. Escaler, E. Egusquiza, M. Farhat, F. Avellan, M. Coussirat, Detection of cavitation in hydraulic turbines, Mech. syst. Signal Pr. 20(2006) 983-1007.

[9] X.L. Chang, X.H. Liu, W. Zhou, Hydropower in China at present and its further development, Energy 35(2010) 4400-06.

[10] N. Kishor, R.P. Saini, S.P. Singh, A review on hydropower plant models and control. Renew, Sust. Energ. Rev. 11(2007) 776-796. 
[11] P. Pennacchi, S. Chatterton, A. Vania, Modeling of the dynamic response of a Francis turbine, Mech. syst. Signal Pr. 29(2012) 107-119.

[12] D.Y. Chen, C. Ding, Y.H. Do, X.Y. Ma, H. Zhao, Y.C. Wang, Nonlinear dynamic analysis for a Francis hydro-turbine governing system and its control, J. Franklin. I. 351(2014) 4596-4618.

[13] S.R. Shakya, R.M. Shrestha, Transport sector electrification in a hydropower resource rich developing country: energy security, environmental and climate change co-benefits, Energy Sustainable Dev. 15(2011) 147-159.

[14] Y. Zeng, Y.K. Guo, L.X. Zhang, T.M. Xu, H.K. Dong, Nonlinear hydro turbine model having a surge tank, Math. Comput. Model. Dyn. Syst. 19(2013) 12-28.

[15] S.P. Wei, Simulation of hydraulic turbine regulating system, first ed, Wuhan: Huazhong University of Science \& Technology Press, China, 2011.

[16] P. Baraldi, F. Di Maio, M. Rigamonti, E. Zio, R. Seraoui, Clustering for unsupervised fault diagnosis in nuclear turbine shut-down transients, Mech. syst. Signal Pr. 58-59(2015) 160-178.

[17] M.T. Ozdemir, M. Sonmez, A. Akbal, Development of FPGA based power flow monitoring system in a microgrid, Int. J. Hydrog. Energ. 39(2014) 8596-8603.

[18] R.R. Chilipi, B. Singh, S.S. Murthy, S. Madishetti, G. Bhuvaneswari, Design and implementation of dynamic electronic load controller for three-phase self-excited induction generator in remote small-hydro power generation, IET Renew. Power Generat. 8(2014) 269-280. 
[19] R.E. Doan, K. Natarajan, Modeling and control design for governing hydroelectric turbines with leaky wicket gates, IEEE Trans. Energy Convers. 19(2004) 449-455.

[20] D.J. Ling, Bifurcation and chaos of hydraulic turbine governor[D], Nanjing: Hohai Universtiy, China, 2007.

[21] A. Bielecki, T. Barszcz, M. Wojcik, Modelling of a chaotic load of wind turbines drivetrain, Mech. syst. Signal Pr. 54-55(2015) 491-505.

[22] E. Egusquiza, C. Valero, A. Presas, X.X. Huang, A. Guardo, U. Seidel, Analysis of the dynamic response of pump-turbine impellers. Influence of the rotor, Mech. syst. Signal Pr. 68-69(2016) 330-341.

[23] Prabha Kundur, Power System Stability and Control. (McGraw-Hill Education, the United States, 1994).

[24] IEEE Working Group, Hydraulic-turbine and turbine control-models for system dynamic studies. IEEE Trans. Power Syst. 7(1992) 167-179.

[25] H.Q. Fang, L. Chen, Z.Y. Shen, Application of an improved PSO algorithm to optimal tuning of PID gains for water turbine governor, Energ. Conv. Manag. 52(2011) 1763-1770.

[26] O. Cerman, P. Husek, Adaptive fuzzy sliding mode control for electro-hydraulic servo mechanism, Expert Syst. Appl. 39(2012) 10269-10277.

[27] M.H. Shou, X.B. Zhang, Study on the dynamic model of the hydro-turbine linear control system, J Electr Eng 4(1984) 48-57. 
[28] J.S. Chang, Transients of hydraulic machine installations, first ed, Higher Education Press, BeiJing, 2005.

[29] Krivchenko(Russia), translated by Z.T. Chang, W.T. Zhou, P.H. Wu, The power device of a hydropower station in the transient process, first ed, Hydraulic press, BeiJing, 1981.

[30] D. Kahaner, C. Moler, S. Nash, Numerical methods and software. (Prentice-Hall, New Jersey, 1989).

[31] R.E. Bank, W.C. Coughran, Jr., W. Fichtner, E. Grosse, D. Rose, R. Smith, Transient simulation of silicon devices and circuits, IEEE Trans. CAD, 4 (1985) $436-451$

[32] L.F. Shampine, Numerical solution of ordinary differential equations. (Chapman \& Hall, New York, 1994).

[33] G. Forsythe, M. Malcolm, C. Moler, Computer Methods for Mathematical Computations. (Prentice-Hall, New Jersey, 1977).

[34] J.R. Dormand, P.J. Prince, A family of embedded Runge-Kutta formulae, J. Comp. Appl. Math. 6(1980) 19-26.

Figure Captions List

Fig. 1 The structure diagram of the Francis hydro-turbine governing system

Fig. 2 The dynamic model of the hydro-turbine and penstock system

Fig. 3 The opening law of the guide vane in the process of sudden load increase transient 
Fig. 4 The change laws of the characteristic parameters of the HTGS in the process of sudden load increase transient

Fig. 5 Curves of six transfer coefficients of the hydro-turbine

Fig. 6 Bifurcation diagrams of the HTGS with time $t$

Fig. 7 Time waveforms of the HTGS with $t=0$

Fig. 8 Time waveforms of the HTGS with $t=0.947$

Fig. 9 Time waveforms of the HTGS with $t=1.063$

Fig. 10 Time waveforms of the HTGS with $t=2$

Fig. 11 Time waveforms of the HTGS with $t=3.05$

Fig. 12 Time waveforms of the HTGS with $t=4.6$

Fig. 13 Zero-pole distributive charts of the HTGS at different representative times

Fig. 14 The comparison of bifurcation diagrams of the HTGS between the novel mathematical model and the previous mathematical model

Fig. 15 Time waveforms of the HTGS of the previous mathematical model 